\title{
Versatile Approach for Preparing PVC-based Mikto-Arm Star Additives Based on RAFT Polymerization
}

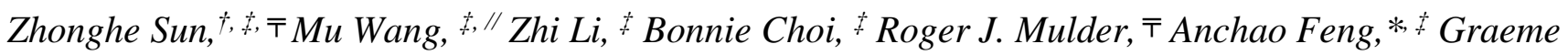 \\ Moad, ${ }^{*}, \bar{\top}$ San H. Thang ${ }^{*}, \dot{t}, \bar{\tau}, \S$
}

${ }^{\dagger}$ Key Laboratory of Bio-Inspired Smart Interfacial Science and Technology of Ministry of Education School of Chemistry, Beihang University, Beijing 100191, China

${ }^{\ddagger}$ Beijing Advanced Innovation Center for Soft Matter Science and Engineering, College of Materials Science and Engineering, Beijing University of Chemical Technology, Beijing 100029, China

TCommonwealth Scientific and Industrial Research Organization (CSIRO) Manufacturing, Clayton, Victoria 3168, Australia

${ }^{\S}$ School of Chemistry, Monash University, Clayton Campus, Victoria 3800, Australia

"Sinopec Research Institute of Petroleum Engineering, Beijing 10001, China

*To whom correspondence should be addressed.

Email:fengac@mail.buct.edu.cn,graeme.moad@csiro.au, san.thang@monash.edu 
1. Synthesis of X-PVC-(CPTDA) 2 - additional characterization data.

(a)
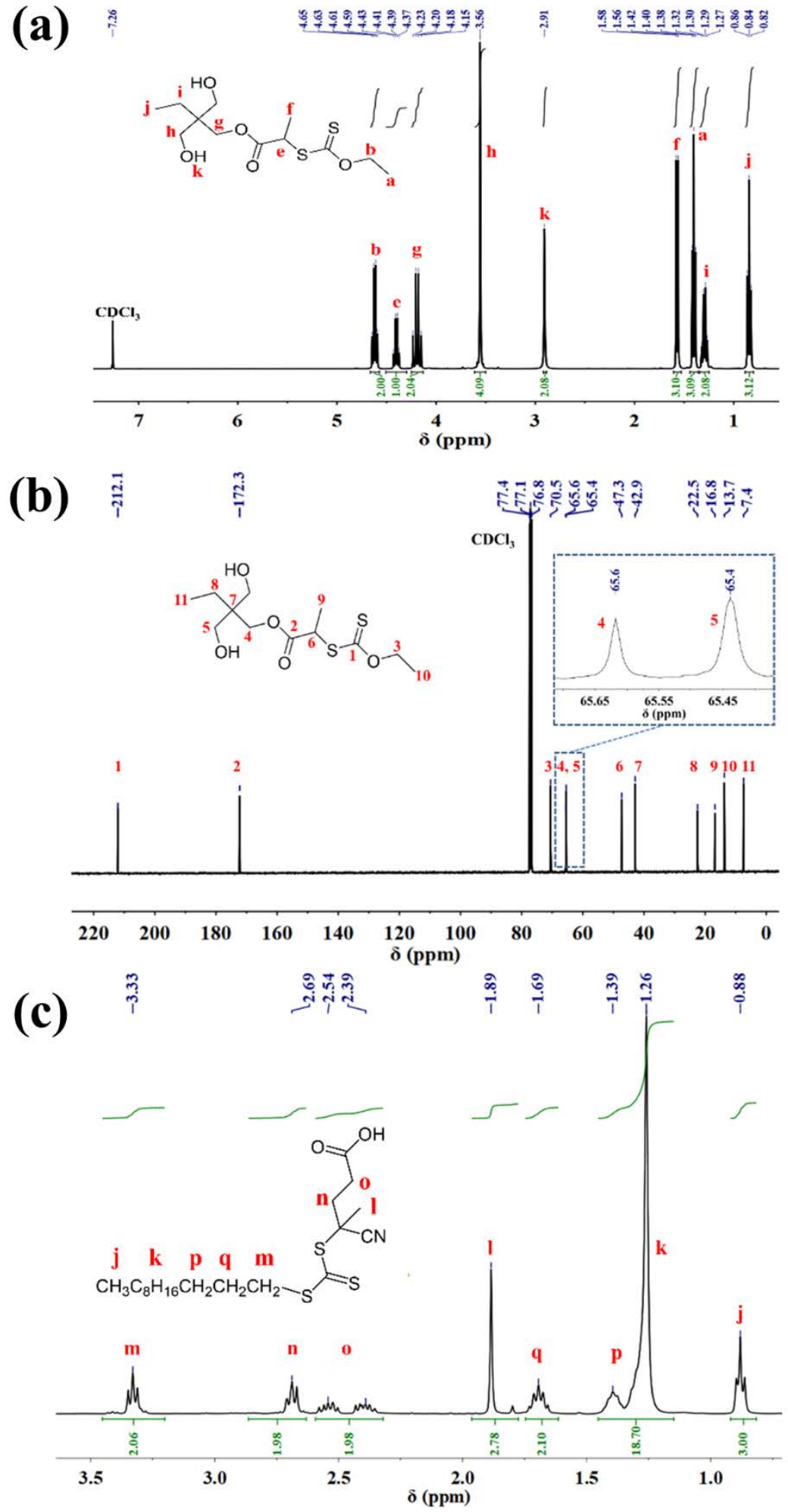

Figure S1. (a) ${ }^{1} \mathrm{H}$ NMR and (b) ${ }^{13} \mathrm{C}$ NMR spectrum of RAFT agent xanthate-(OH) (5) and (c) ${ }^{1} \mathrm{H}$ NMR spectrum of trithiocarbonate CDTPA all in $\mathrm{CDCl}_{3}$ 
(a)

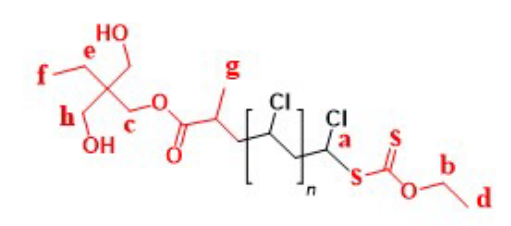

1,4-dioxane

a
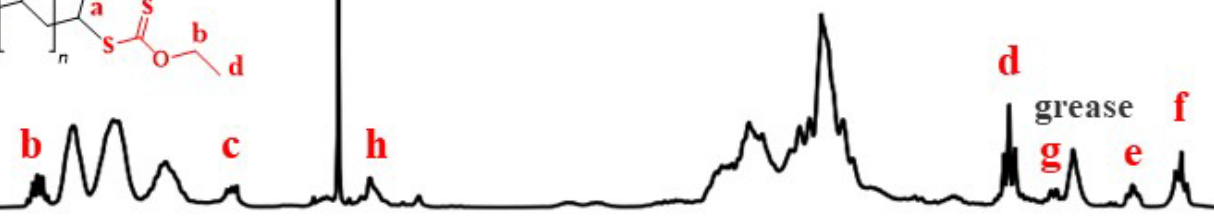

(b)

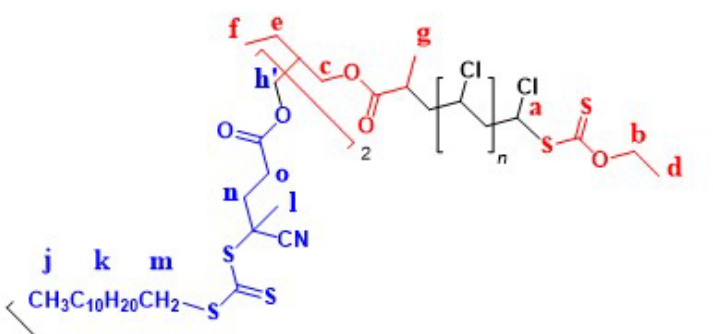

a

b $M \sim^{\mathrm{c}+\mathrm{h}^{\prime}} \mathrm{h}$ ? $\mathrm{m}$

0

(c)

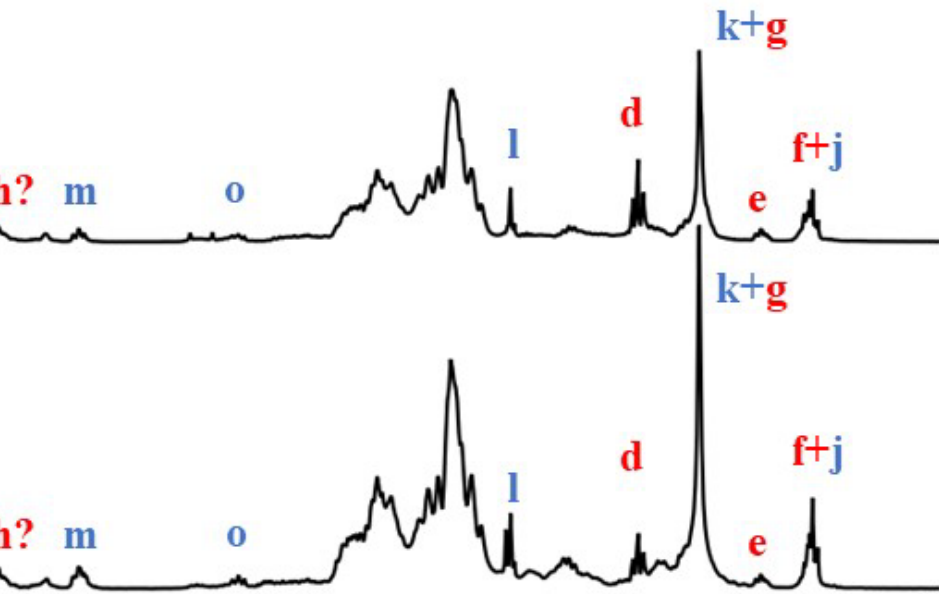

a

c+h'

h? $\mathrm{m}$

2

1

65

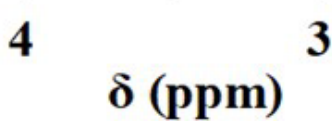

Figure S2. ${ }^{1} \mathrm{H}$ NMR spectra $\left(\mathrm{CDCl}_{3}\right)$ of (a) X-PVC- $(\mathrm{OH})_{2}\left(M_{\mathrm{n}}=7200, \emptyset=1.36\right)$, (b) X-PVC-(CDTPA $)_{2}$ $\left(M_{\mathrm{n}}=7600, \emptyset=1.37\right)$, and (c) X-PVC-(CDTPA $)_{2}\left(M_{\mathrm{n}}=10200, \emptyset=1.21\right)$. The integration of peaks 'a', 'b' (xanthate end) and ' $m$ ' (trithiocarbonate ends) suggests structure for (b) may be more consistent with XPVC-(OH)(CDTPA), while (c) is consistent with X-PVC-(CDTPA) $)_{2}$ - see text.

Note that the ${ }^{1} \mathrm{H}$ NMR assignment for $-\mathrm{CHCl}-\mathrm{CHS}\left(\mathrm{C}=\mathrm{S}\right.$ )- (peak 'a') indicated in our pervious paper ${ }^{1}$ was incorrect.

Signals assigned to dioxane and grease in Figure 2c on the basis of the DOSY spectrum (the have a relatively short spin correlation time).

Both ' $h$ ' and the methine next to ' $g$ ' should appear in the region 3.5-4 ppm. The peak designated as h? is part of the polymer as evidenced by the DOSY spectrum (it has the same spin correlation time as the polymer). However, this peak does not diminish in a consistent manner as a consequence of Steglich esterification. The similar peaks appear in the ${ }^{1} \mathrm{H}$ NMR spectrum of $(\mathrm{X}-\mathrm{PVC})_{2}-(\mathrm{OH})_{2}$ and $(\mathrm{X}-\mathrm{PVC})_{2}-(\mathrm{CDTPA})_{2}$ (Figure S3). 
Table S1. Calculated and experimentally found (in parentheses) composition of RAFT agents from elemental analysis

\begin{tabular}{ccccc}
\hline Sample & $\mathrm{N}(\%)$ & $\mathrm{C}(\%)$ & $\mathrm{H}(\%)$ & $\mathrm{S} \mathrm{( \% )}^{\mathrm{d}}$ \\
\hline X-PVC-(OH) ${ }^{\mathrm{a}}$ & $0(0.04)$ & $38.90(39.81)$ & $4.97(5.05)$ & $1.19(1.19)$ \\
X-PVC-(OH)(CDTPA) $^{\mathrm{b}}$ & $0.25(0.53)$ & $39.77(41.20)$ & $5.09(5.12)$ & $2.03(2.02)$ \\
CDTPA $^{\mathrm{c}}$ & $3.47(4.15)$ & $56.54(56.71)$ & $8.24(8.08)$ & $23.83(21.34)$ \\
\hline
\end{tabular}

${ }^{a}$ Data are for X-PVC-(OH) $2, M_{\mathrm{n}, \mathrm{GPC}}=7200$ (polystyrene equivalents), $\oslash=1.36$.

The full calculated best fit data are

Chemical Formula: $\mathrm{C}_{174} \mathrm{H}_{265} \mathrm{Cl}_{81} \mathrm{O}_{5} \mathrm{~S}_{2}$

Molecular Weight: 5372.60

Elemental Analysis: C, 38.90; H, 4.97; Cl, 53.45; O, 1.49; S, 1.19

${ }^{\mathrm{b}}$ Consistent with X-PVC-(OH)(CDTPA). $M_{\mathrm{n}, \mathrm{GPC}}=7600$ (polystyrene equivalents), $Ð=1.37$.

The full calculated best fit data are

Chemical Formula: $\mathrm{C}_{261} \mathrm{H}_{398} \mathrm{Cl}_{115} \mathrm{NO}_{6} \mathrm{~S}_{5}$

Molecular Weight: 7883.11

Elemental Analysis: $\mathrm{C}, 39.77 ; \mathrm{H}, 5.09 ; \mathrm{Cl}, 51.72 ; \mathrm{N}, 0.18 ; \mathrm{O}, 1.22 ; \mathrm{S}, 2.03$

${ }^{\mathrm{c}} \mathrm{CDTPA}$ has $M=403.7, \mathrm{C}_{19} \mathrm{H}_{33} \mathrm{O}_{2} \mathrm{NS}_{3}$.

The calculated values shown in Table S1 were obtained by adjusting the PVC chain length to provide a best fit to the experimentally found data. The product of Steglich esterification is most consistent with X-PVC$(\mathrm{OH})(\mathrm{CDTPA})$. The value of \%S taken alone is consistent with a conversion in the Steglich esterification of $87 \%$ in the structure is X-PVC-(CDTPA) 2 . However, the values of $\% \mathrm{C}$ and $\% \mathrm{H}$ are inconsistent with this. The structure X-PVC-(OH)(CDTPA) is consistent with the ${ }^{1} \mathrm{H}$ NMR and the relative integration of the peaks ' $a$ ', 'b' and 'm' (Figure S1b).

It should be noted that the ${ }^{1} \mathrm{H}$ NMR spectra displayed in Figure S2 are not quantitative. The NMR conditions were such as to accentuate the signals associated with the end groups. They should not be used to directly compare signals attributable to end groups with those associated with the PVC backbone.

We believe that X-PVC- $(\mathrm{OH})_{2}$ may be too sterically congested to permit easy installation of two trithiocarbonate groups by DCC-mediated esterification. To test this hypothesis, models based on a 10-unit PVC chain were constructed in CHEM-3D and the energies minimized using MM2. ${ }^{2}$ The structures generated are shown in Figure S3. 

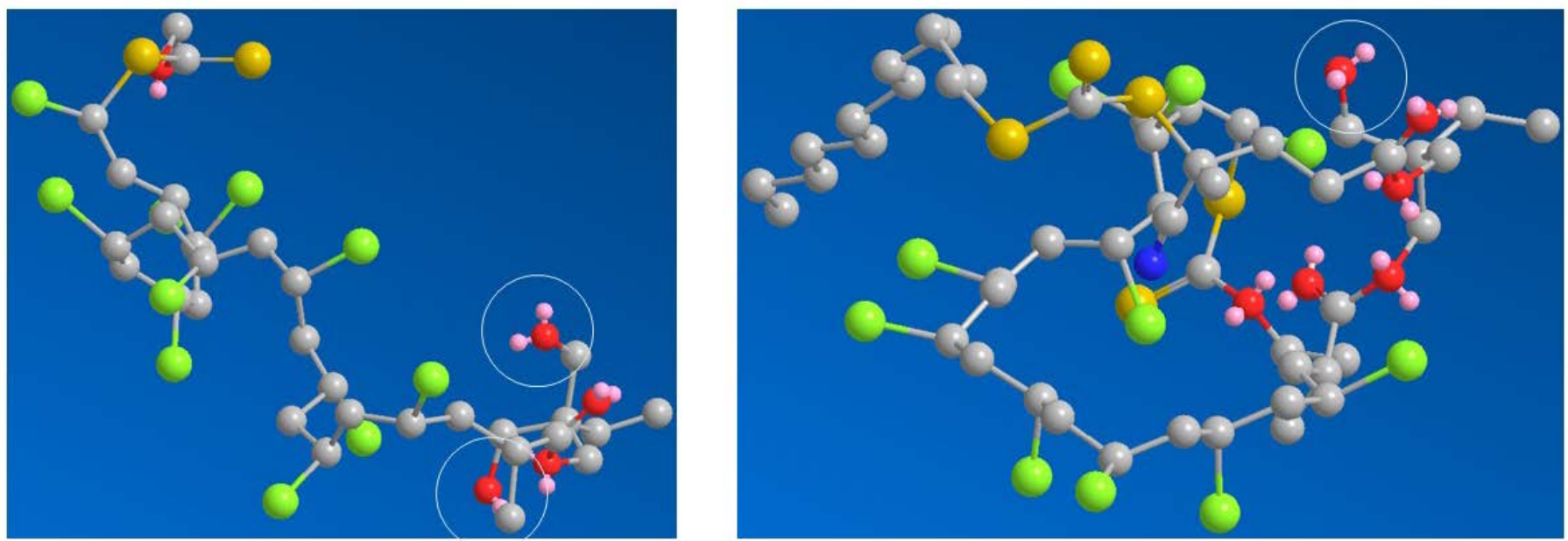

Figure S3. Structures for X-PVC-(OH) 2 (left) and X-PVC-(OH)(CDTPA) (right) generated with CHEM-3D (version 16.0.1.4) after applying the default MM2 energy minimization (carbon - grey, chlorine - green, oxygen - red, lone pair - pink, the hydrogen atoms are hidden). The hydroxyl groups are circled.

The conditions for Steglich esterification, which provided, within experimental error estimated as , the desired X-PVC-(CDTPA) 2 ( ${ }^{1} \mathrm{H}$ NMR in Figure S2b) were not different to those which provided X-PVC-(OH)(CDTPA) $\left({ }^{1} \mathrm{H}\right.$ NMR in Figure S2c). We believe the difference in outcome is due the presence of trace amount of water in the solvents used.

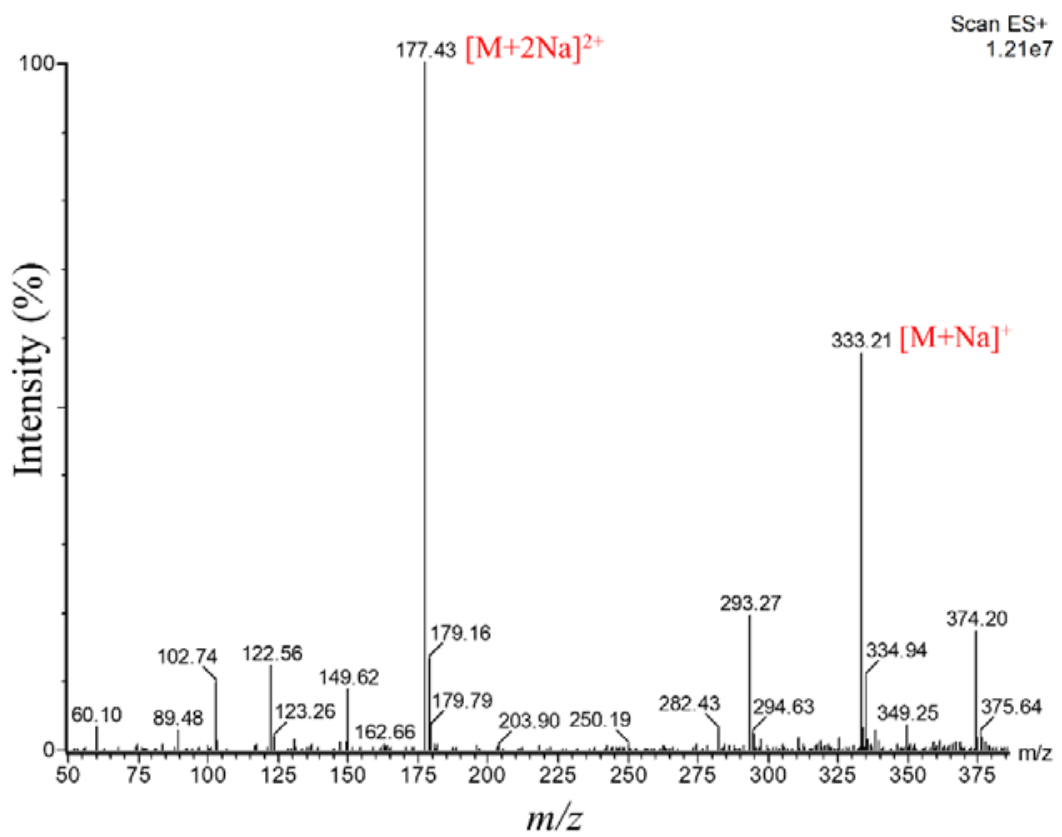

Figure S4. MS-ESI spectrum of RAFT agent xanthate- $(\mathrm{OH})_{2}(M=310.4)$ in positive ion mode in acetonitrile. 


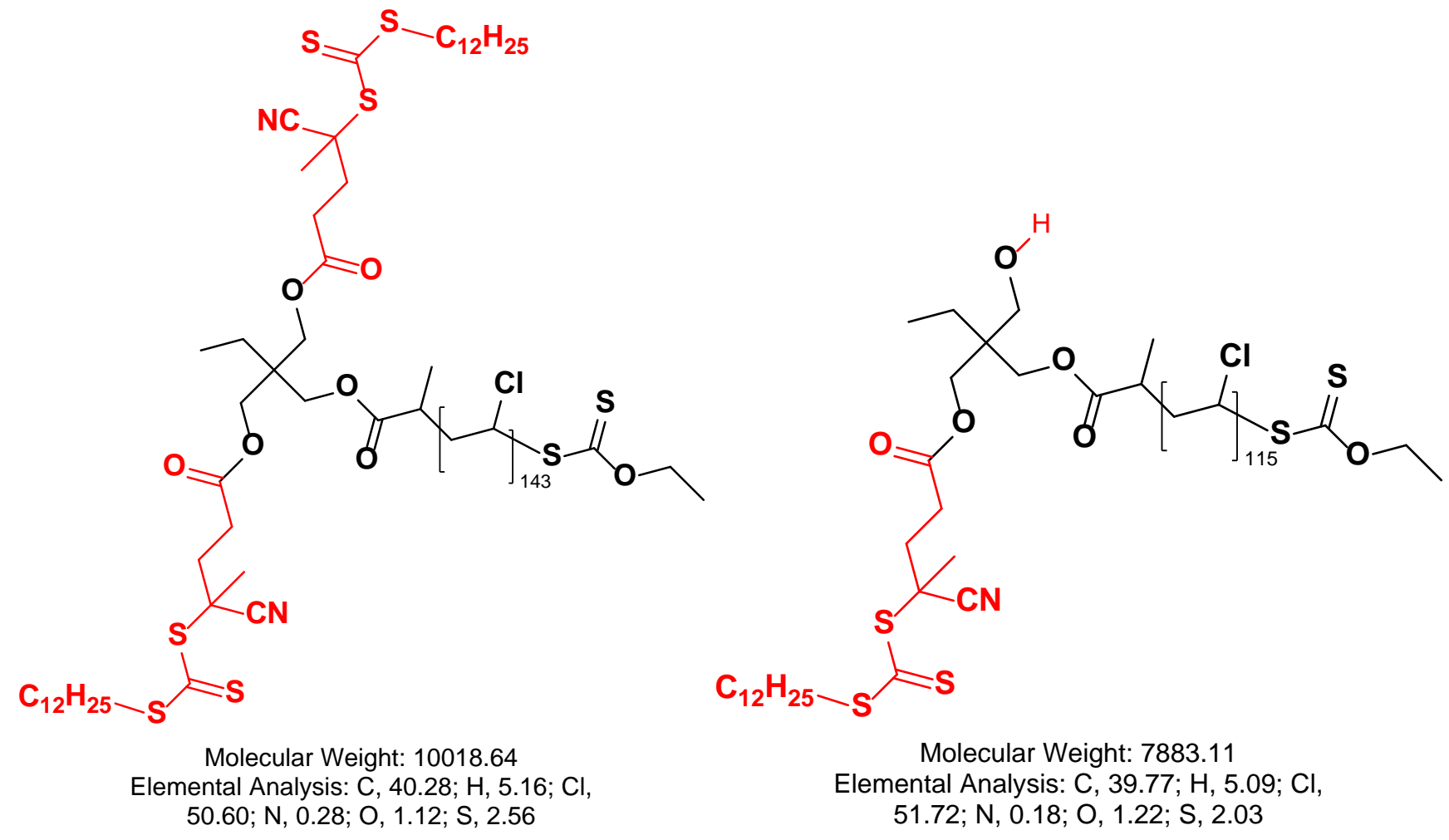

Figure S5. Calculated molar mass and composition for X-PVC-(CDTPA) $)_{2}$ and X-PVC-(OH)(CDTPA)

\section{Synthesis of (X-PVC)2-(CPTDA)2 .}

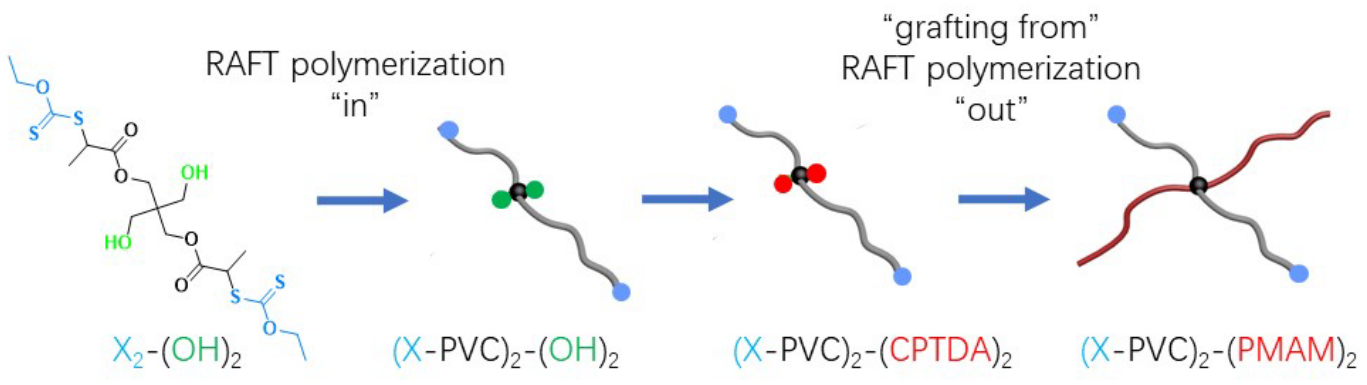

Scheme S1. Strategy for $A_{2} B_{2} 4$-mikto-arm star synthesis.

The synthesis and characterization of (X-PVC) 2 -(CPTDA) 2 , a potential precursor to an $\mathrm{A}_{2} \mathrm{~B}_{2} 4$-mikto-arm star according to Scheme S1, is presented here. The analysis facilitated ${ }^{1} \mathrm{H}$ NMR characterization of the 3mikto arm precursor X-PVC-(CPTDA)2. The NMR of (X-PVC) 2 -(CPTDA) 2 , is simplified by symmetry. 
<smiles>OCC(CO)(CO)CO</smiles><smiles>COC(C)(C)OCCO</smiles>
$\mathrm{sOH}$ $\mathbf{2}^{\prime}$ (Yield=30\%)

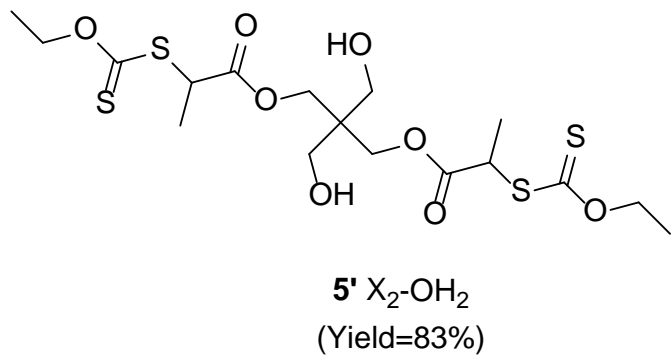

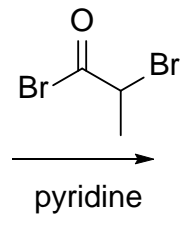

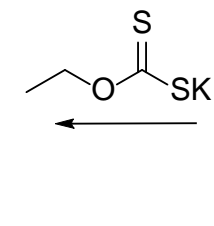

Scheme S2. Synthesis of RAFT agent, $\mathrm{X}_{2}-(\mathrm{OH})_{2}\left(\mathbf{5}^{\prime}\right)$

The synthetic route leading to $\mathrm{X}_{2}-(\mathrm{OH})_{2}$ is shown in Scheme S2. The procedure for preparing 4' is based on literature procedures ${ }^{3-5}$ for synthesizing the corresponding isobutyrate derivatives.

2,2-Dimethyl-5,5-bis(hydroxymethyl)-1,3-dioxane (2'). Pentaerythritol (1') (10 g, 73.53 mmol), ptoluenesulfonic acid $(0.122 \mathrm{~g}, 0.88 \mathrm{mmol})$ and DMF $(125 \mathrm{~mL})$ were placed in a $250 \mathrm{~mL}$ round-bottom flask. The mixture was heated at $80{ }^{\circ} \mathrm{C}$ until dissolution and then allowed to cool. When the temperature reached 40 ${ }^{\circ} \mathrm{C}$, f 2,2-dimethoxypropane ( $8.52 \mathrm{~mL}, 73.53 \mathrm{mmol}$ ) was added and the reaction was allowed to proceed for $48 \mathrm{~h}$. The solution was filtered, and the solvent was evaporated under reduced pressure. The crude product was extracted in a Soxhlet apparatus with petroleum ether (bp $30{ }^{\circ} \mathrm{C}-60{ }^{\circ} \mathrm{C}$ ) for $12 \mathrm{~h}$ and then diethyl ether for $12 \mathrm{~h}$, respectively. The final product 2,2-Dimethyl-5,5-bis(hydroxymethyl)-1,3-dioxane (2') was obtained as white crystals from the extract after evaporation under reduced pressure (4.60 g, 30\% yield).

(2,2-dimethyl-1,3-dioxane-5,5-diyl)bis(methylene) bis(2-bromopropanoate) (3'). 2,2-Dimethyl-5,5bis(hydroxymethyl)-1,3-dioxane (2') (6 g, $34.1 \mathrm{mmol})$, triethylamine (9.40 mL, $68.2 \mathrm{mmol}$ ) and anhydrous THF (100 mL) were added to a $250 \mathrm{~mL}$ round bottom flask which was immersed in an ice bath, and then 2bromopropionyl bromide ( $3.68 \mathrm{~mL}, 34.1 \mathrm{mmol}$ ) was added dropwise by syringe. The solution was stirred at room temperature for $24 \mathrm{~h}$. The solution was filtered, and the solvent was evaporated by rotary evaporation. The crude product was dissolved in dichloromethane and washed with water $(\mathrm{pH}=9)$. The separated organic layer was dried $\left(\mathrm{MgSO}_{4}\right)$ and the solvent evaporated under reduced pressure to provide (2,2-dimethyl-1,3dioxane-5,5-diyl)bis(methylene) bis(2-bromopropanoate) (3’) (12.25 g, 75\% yield).

2,2-bis(hydroxymethyl)propane-1,3-diyl bis(2-bromopropanoate) (4'). (2,2-dimethyl-1,3-dioxane-5,5diyl)bis(methylene) bis(2-bromopropanoate) (3’) (2.23 g, $5 \mathrm{mmol}$ ), $150 \mathrm{~mL} \mathrm{CHCl}_{3}$ and $50 \mathrm{~mL}$ of $80 \%$ acetic acid were added to a $500 \mathrm{ml}$ round-bottom flask. The solution was stirred at room temperature overnight. Then, additional $100 \mathrm{~mL}$ of $80 \%$ acetic acid were added and the mixture was refluxed for $1 \mathrm{~h}$ at $80{ }^{\circ} \mathrm{C}$. The crude product was recovered after evaporation of $\mathrm{CHCl}_{3}$ and acetic acid under reduced pressure, and then was washed with water and dried under a hood for $48 \mathrm{~h}$. The crude product 2,2-bis(hydroxymethyl)propane-1,3diyl bis(2-bromopropanoate) (4') was purified by preparative TLC (petroleum ether/ethyl acetate $=1: 2, \mathrm{v} / \mathrm{v}$ ) (0.95 g, 52\% yield).

2,2-bis(hydroxymethyl)propane-1,3-diyl bis(2-((ethoxycarbonothioyl)thio)propanoate) $\left(\mathrm{X}_{2}-(\mathrm{OH})_{2}\right)$ (5'). A solution of 2,2-bis(hydroxymethyl)propane-1,3-diyl bis(2-bromopropanoate) (4') (8.2 g, $20 \mathrm{mmol}$ ) in acetone $(15 \mathrm{~mL})$ was added dropwise to a solution of potassium $O$-ethylcarbonodithioate $(14.6 \mathrm{~g}, 90 \mathrm{mmol})$ 
in acetone $(45 \mathrm{~mL})$ at room temperature over $30 \mathrm{~min}$, and the mixture stirred for $12 \mathrm{~h}$ at room temperature. The mixture filtered and the acetone evaporated under reduced pressure. The residue was dissolved in dichloromethane $(100 \mathrm{~mL})$, washed with water $(3 \times 100 \mathrm{~mL})$, dried $\left(\mathrm{MgSO}_{4}\right)$ and the solvent evaporated under reduced pressure to yield 2,2-bis(hydroxymethyl)propane-1,3-diyl bis(2((ethoxycarbonothioyl)thio)propanoate) (xanthate $-(\mathrm{OH})_{2}$ ) as a viscous yellow oil (5.2 g, 83\% yield). ${ }^{1} \mathrm{H}$ NMR (400 MHz, $\mathrm{CDCl}_{3}$, Figure S) $\delta 4.61(4 \mathrm{H}, \mathrm{q}, J=7.1 \mathrm{~Hz}$ ), $4.38(2 \mathrm{H}, \mathrm{q}, J=7.4 \mathrm{~Hz}$ ), $4.14(4 \mathrm{H}, \mathrm{q}, J=11.4 \mathrm{~Hz})$, $3.59(4 \mathrm{H}, \mathrm{s}), 2.83(2 \mathrm{H}, \mathrm{s}), 1.55(6 \mathrm{H}, \mathrm{d}, J=7.4 \mathrm{~Hz}), 1.40(6 \mathrm{H}, \mathrm{t}, J=7.1 \mathrm{~Hz})$. The NMR spectra is provided in Figure S3a

(X-PVC)2-(OH)2. The procedure was similar to that described for RAFT polymerization of vinyl chloride in the Experimental section of the paper. The molar ratio of [M]:[CTA]:[I] was 200:1:0.15, and precondensed VC (6.6 g, $106 \mathrm{mmol})$, xanthate2-(OH)2 (5’) (0.16 g, $0.53 \mathrm{mmol})$, ABVN (0.02 g, $0.08 \mathrm{mmol})$, and 1,4dioxane $(15 \mathrm{~mL})$ were added to the high pressure reactor and reacted at $45{ }^{\circ} \mathrm{C}$ for $60 \mathrm{~h}$. The (X-PVC)2-(OH)2 (3.50 g, 53\%) formed was separated and dried to constant weight. The NMR spectra for a sample of (XPVC)2-(OH)2 $\left(M_{\mathrm{n}, \mathrm{th}}=12900 \mathrm{Da}, M_{\mathrm{n}, \mathrm{GPC}}=14500\right.$ (polystyrene equivalents), $\left.D=1.29\right)$ is provided in Figure S3b.

(X-PVC)2-(CDTPA)2. The procedure was similar to that used for the preparation of X-PVC-(CDTPA $)_{n}$ by esterification of X-PVC- $(\mathrm{OH})_{n}$ in theExperimental Section of the paper. A solution of (X-PVC $)_{2}-(\mathrm{OH})_{2}(2.0$ g, $0.2 \mathrm{mmol})$, DCC (0.16 g, $0.8 \mathrm{mmol})$, CDTPA (0.23 g, $0.6 \mathrm{mmol})$ and DMAP (0.001 g, $0.01 \mathrm{mmol})$ in dry 1,4-dioxane $(15 \mathrm{~mL})$ were heated at $45^{\circ} \mathrm{C}$ for $12 \mathrm{~h}$. Then the esterified PVC-(CDTPA) 2 (1.72 g, 86\%) was separated and dried to constant weight. The NMR spectra for a sample of (X-PVC) 2 -(CDTPA) 2 $\left(M_{\mathrm{n}, \mathrm{GPC}}=14900\right.$ polystyrene equivalents, $\left.Ð=1.30\right)$ is provided in Figure S3c.

NMR spectra. The NMR of (X-PVC $)_{2}-(\mathrm{OH})_{2}$ and (X-PVC $)_{2}-(\mathrm{CDTPA})_{2}$ are simplified by symmetry vs the corresponding spectra of the 3-mikto-arm star precursors. Although it is tempting to assign ' $h$ ' as indicated the peak in Figure S3b is too small. Moreover, this peak does not substantially decrease in Figure S3c when it should vanish. Both ' $h$ ' and the methine next to 'g' should appear in the region 3.5-4 ppm. 

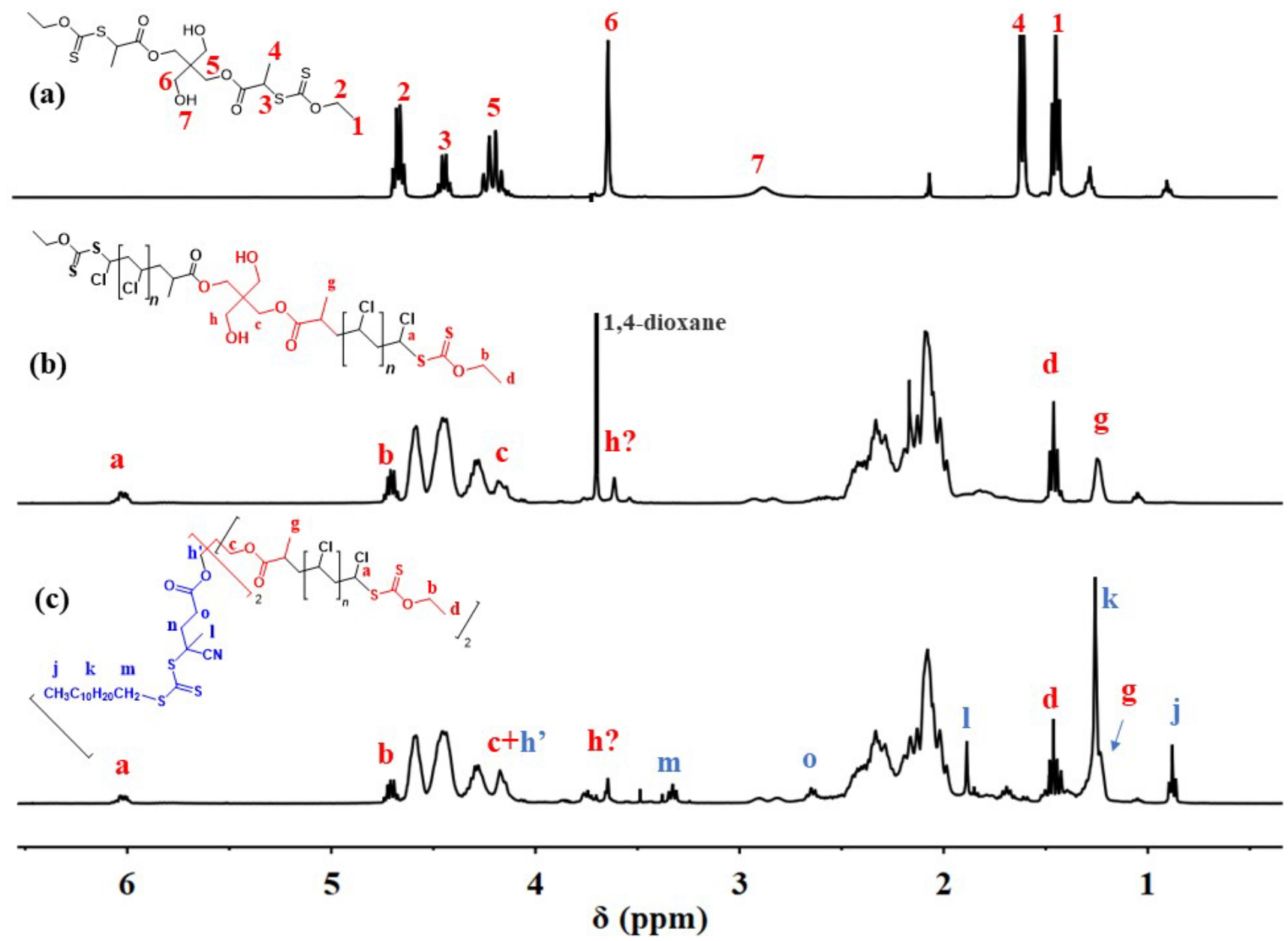

Figure S6. ${ }^{1} \mathrm{H}$ NMR spectra $\left(\mathrm{CDCl}_{3}\right)$ of (a) $\mathrm{X}_{2}-(\mathrm{OH})_{2}$, (b) $(\mathrm{X}-\mathrm{PVC})_{2}-(\mathrm{OH})_{2}\left(M_{\mathrm{n}}=14500, Ð=1.29\right)$, and (c) $(\mathrm{X}-\mathrm{PVC})_{2}-(\mathrm{CDTPA})_{2}\left(M_{\mathrm{n}}=14900, Ð=1.30\right)$. 


\section{Experiments with linear X-PVC-OH and X-PVC-CPTDA}

(a)

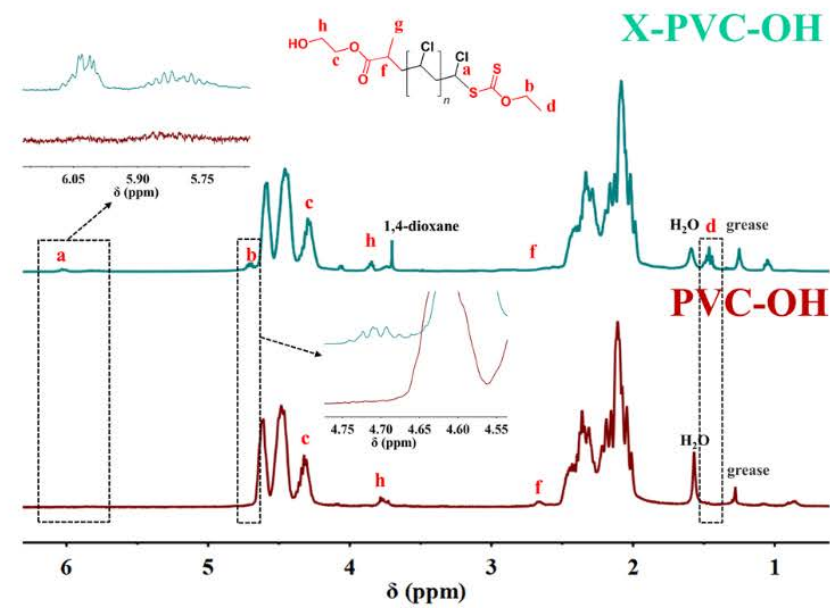

(b)

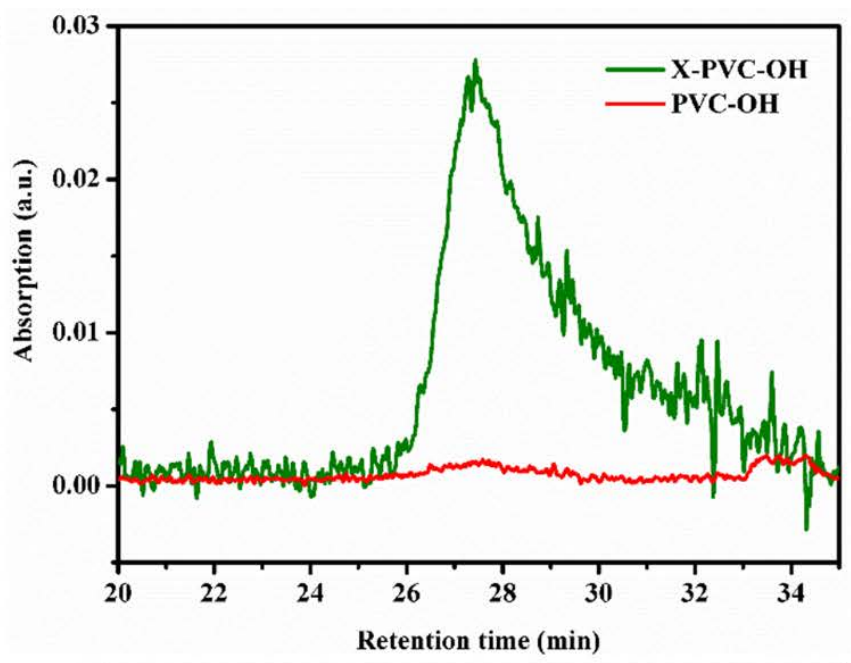

(c)

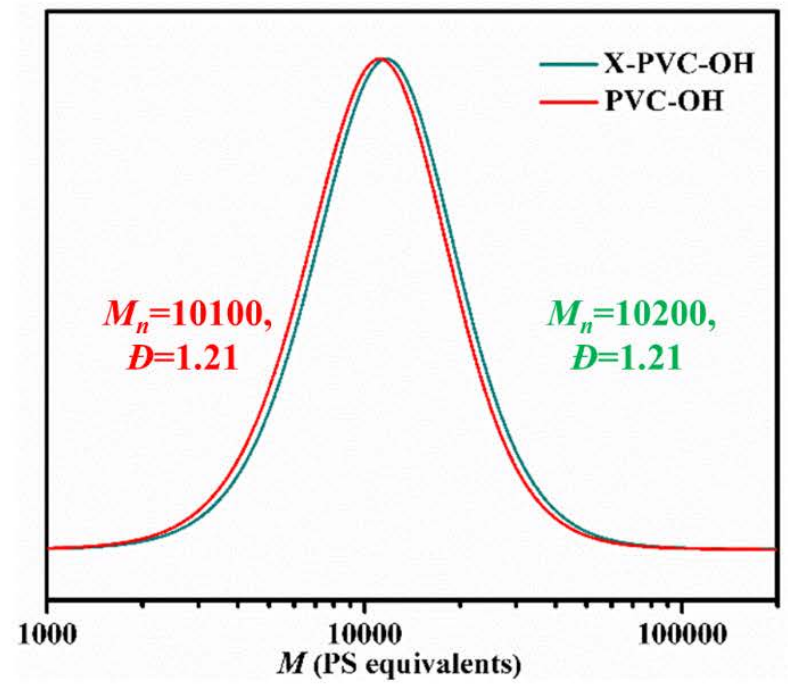

Figure S7. (a) ${ }^{1} \mathrm{H}$ NMR spectra of X-PVC-OH $\left(M_{\mathrm{n}}=10200, D=1.21\right)$ (green line) and PVC-OH $\left(M_{\mathrm{n}}=10100, \emptyset=1.21\right)$ after (red line) removal of xanthate end group; (b) Extracted SEC trace with UV detection for $278 \mathrm{~nm}$ for X-PVC-OH $\left(M_{\mathrm{n}}=10200, Ð=1.21\right)$ (green line) and derived PVC-OH $\left(M_{\mathrm{n}}=10100, \emptyset=1.21\right)$ (red line); (c) SEC traces with refractive index detection for X-PVC-OH $\left(M_{\mathrm{n}}=10200, \emptyset=1.21\right)$ (black line) and derived PVC-OH $\left(M_{\mathrm{n}}=10100, \emptyset=1.21\right)$ (red line). The peaks associated with the xanthate end are indicated by dashed boxes. 
Table S2. Monomer Conversion, $M_{\mathrm{n}}$, and $Ð$ values for polymers formed with different RAFT agents with [BA]:[CTA]:[AIBN] = 80:1:0.2 at $80^{\circ} \mathrm{C}$ for $12 \mathrm{~h}$.

\begin{tabular}{ccccc}
\hline RAFT agent & $\begin{array}{c}\text { conv. }^{\text {a }} \\
(\%)\end{array}$ & $\begin{array}{c}M_{\mathrm{n}, \mathrm{th}}{ }^{\mathrm{b}} \\
(\mathrm{kDa})\end{array}$ & $M_{\mathrm{n}, \mathrm{GPC}}{ }^{\mathrm{c}}$ & $Ð$ \\
\hline CDTPA & 93.4 & 10.0 & 9.5 & 1.08 \\
HECP & 91.6 & 10.0 & 10.7 & 2.08 \\
$\begin{array}{c}\text { X-PVC-OH } \\
\text { (with xanthate group) }\end{array}$ & 75.3 & 21.5 & 18.9 & 1.75 \\
$\begin{array}{c}\text { X-PVC-CDTPA } \\
\text { (with xanthate group) }\end{array}$ & 90.1 & 21.5 & 24.0 & 1.48 \\
$\begin{array}{c}\text { PVC-CDTPA } \\
\text { (removal of xanthate group) }\end{array}$ & 90.4 & 20.0 & 18.9 & 1.30 \\
$\begin{array}{c}\text { None } \\
\text { (free radical polymerization) }\end{array}$ & 95.7 & - & 35.5 & 2.73 \\
\hline
\end{tabular}
a The conversion of VC monomer was calculated from the mass of monomer in feed and mass of PVC obtained. The
conversion of other monomer was calculated from integration of the ${ }^{1} \mathrm{H}$ NMR spectrum.

b The theoretical molar mass of the polymers was calculated using the formula $M_{\mathrm{n} \text {,th. }}=M_{\mathrm{RAFT}^{+}}(\mathrm{conv} . \times$ [monomer $\times$ $\mathrm{M}_{\text {monomer }}$ / [CTA]. Where $M_{\mathrm{RAFT}}$ and $M_{\text {monomer }}$ are the molar mass of the RAFT agent or macro-RAFT agent, and the monomer, respectively.

c. Molar mass in PS equivalents determined by GPC (see the Experimental Section). Mark Houwink parameters for PVC suggest that absolute $M_{\mathrm{n}}$ values for PVC homopolymers may be $\sim 30 \%$ lower than the values indicated (see Figure S16).

\section{4. ${ }^{1} \mathrm{H}$ NMR DOSY characterization of $\mathrm{AB}_{2} 3$-mikto-arm stars}

The DOSY spectra for the precursor X-PVC $(\mathrm{OH})_{2}$ is shown in Figure S8c. The same precursor was used for making each of the mikto-arm stars. The DOSY spectra for the star-[(PVC-b-B;(B) $\left.)_{2}\right]$ based on various monomers B are shown in Figures S8b, S9b, S10b, S11b, and S12b, the PVC segments and the peaks assigned to the added poly(B) segments the same spin diffusion time which is at least slightly longer than that of the precursor. This is consistent with their being part of the same molecule. The spin diffusion time is related to the molar mass and shape of the star. ${ }^{6}$

The exception is star-[(PVC- $b$-PHABP;(PHABP) $)_{2}$ (Figure S10b). The DOSY spectrum shows different spin correlation times for the signals attributable PHABP are different to and shorter than those for the PVC component. This indicates they are not part of the same macromolecule and that the desired star may only be at best a minor component of the product. 
4.1 star-[(PVC-b-PBA;(PBA)2]. The DOSY peaks for the PBA and PVC components have the same spin correlation time (Figure S8b), consistent with their being part of the same structure, and they have a longer spin correlation time that the precursor X-PVC- $(\mathrm{OH})_{2}$ (Figure S8c), which is consistent with the higher molar mass of the star-[(PVC- $b$-PBA;(PBA $\left.)_{2}\right]$.

(a)

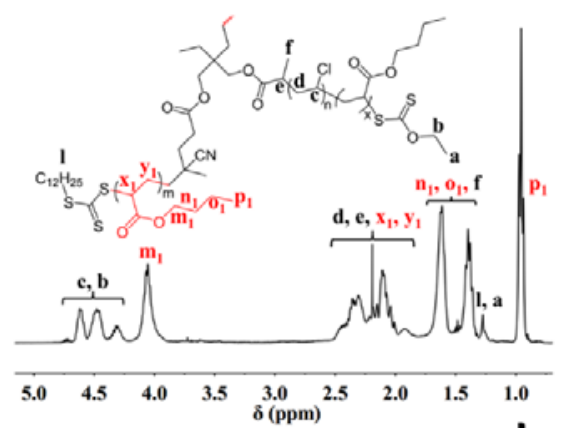

(b)

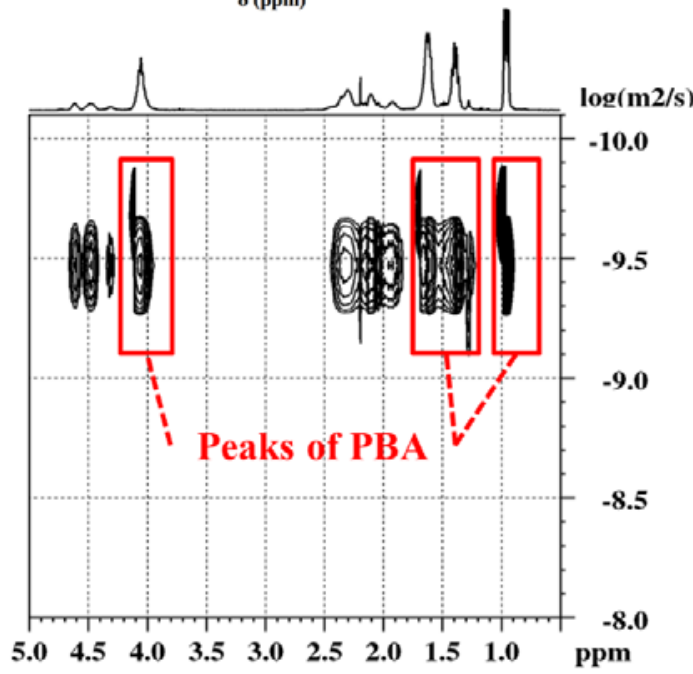

(c)

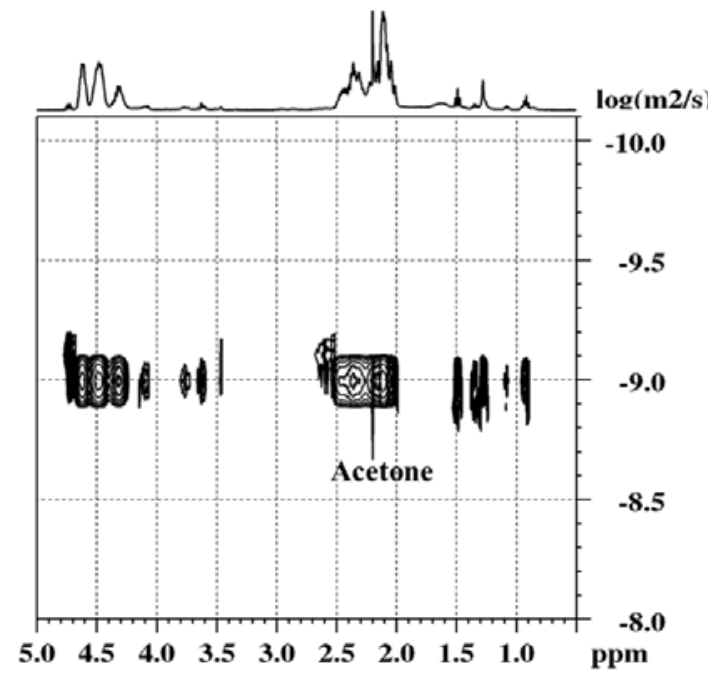

Figure S8. (a) ${ }^{1} \mathrm{H}$ NMR spectrum of star-[(PVC- $b$-PBA; $\left.(\mathrm{PBA})_{2}\right]\left(M_{\mathrm{n}}=23500, Ð=1.52\right)$ copolymer in $\mathrm{CDCl}_{3}$; (b) ${ }^{1} \mathrm{H}$ DOSY spectra $\left(\mathrm{CDCl}_{3}, 400 \mathrm{MHz}, 298 \mathrm{~K}\right)$ for star-[(PVC- $b$-PBA; (PBA) $]\left(M_{\mathrm{n}}=23500, Ð=1.52\right)$; (c) ${ }^{1} \mathrm{H}$ DOSY spectra $\left(\mathrm{CDCl}_{3}, 400 \mathrm{MHz}, 298 \mathrm{~K}\right)$ for X-PVC- $(\mathrm{OH})_{2}\left(M_{\mathrm{n}}=10600, \emptyset=1.34\right)$. 
4.2 star-[(PVC;(PMPS)2]. The DOSY peaks for the PMPS and PVC components have the same spin correlation time (Figure S9b) consistent with their being part of the same structure, namely, star[(PVC;(PMPS) 2 ]. More over the spin correlation time is longer than that of the precursor (Figure S8c), which is consistent with the higher molar mass of the star polymer.

(a)

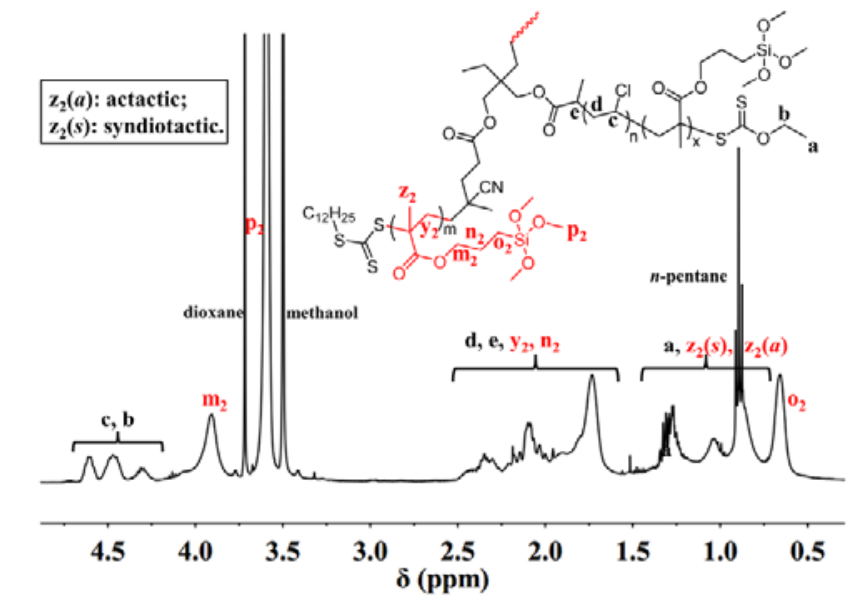

(b)

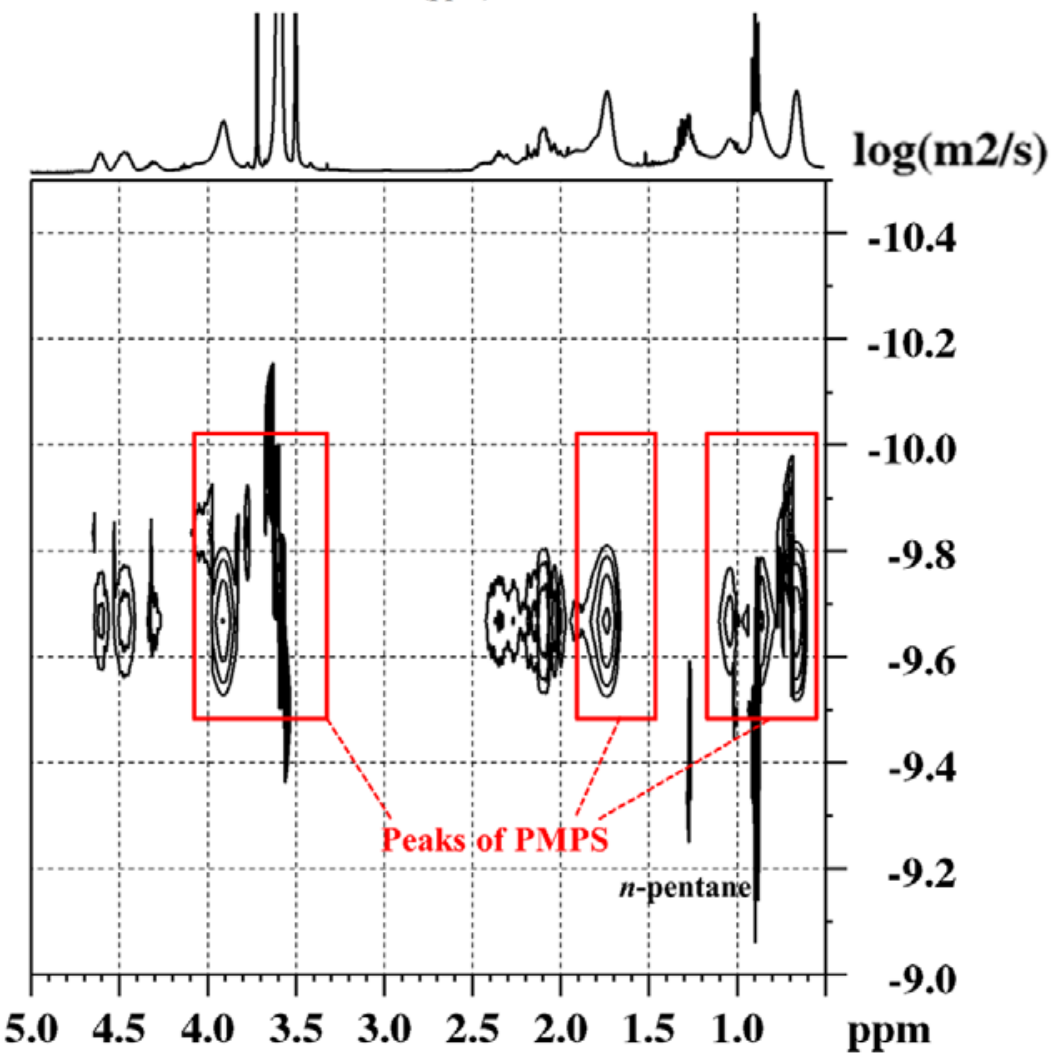

Figure S9. (a) ${ }^{1} \mathrm{H}$ NMR and (b) ${ }^{1} \mathrm{H}$ DOSY spectra $\left(\mathrm{CDCl}_{3}, 400 \mathrm{MHz}, 298 \mathrm{~K}\right)$ for star-[(PVC;(PMPS) $\left(M_{\mathrm{n}}=22200, \oslash=1.50\right)$ copolymer. 
4.3 star-[(PVC-b-PHABP;(PHABP) $\left.)_{2}\right]$. The ${ }^{1} \mathrm{H}$ NMR spectrum of the RAFT polymerization of HABP mediated by PVC-(CDTPA)2 shows peaks for PVC and for PHABP (Figure S10a). The DOSY spectrum shows different spin correlation times for the signals attributable to the PVC and PHABP components (Figure S8b) suggesting they are not part of the same macromolecule, Thus the amount of the desired star-[(PVC- $b$ PHABP;(PHABP $)_{2}$ ] formed may be small. The GPC trace (Figure S14) for star-[(PVC- $b$-PHABP;(PHABP) $\left.)_{2}\right]$ is, however, consistent with chain extension having been successful.

(a)

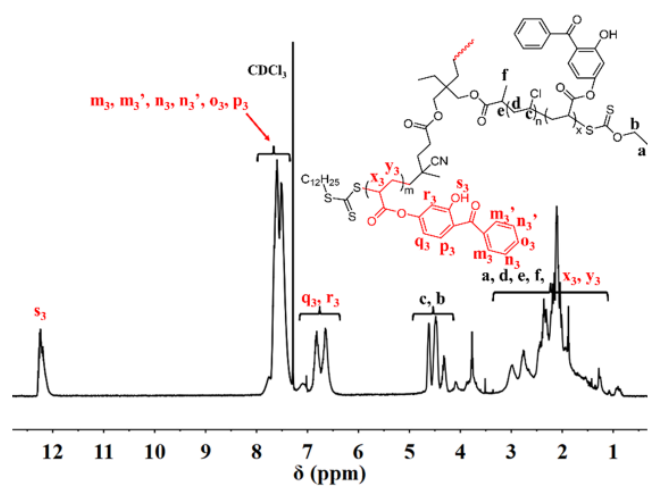

(b)

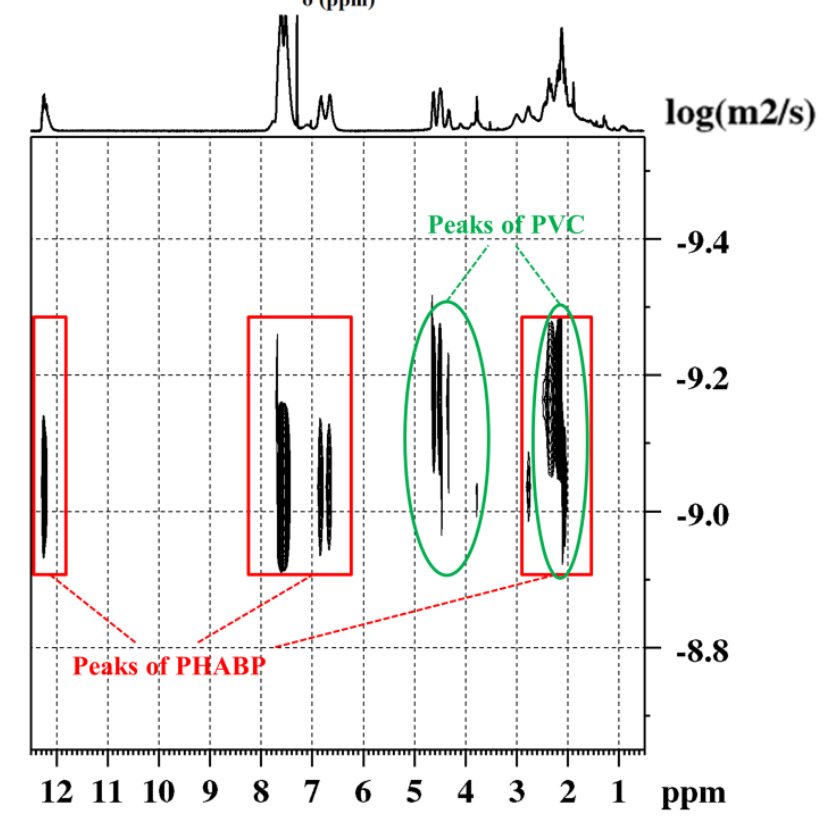

Figure S10. (a) ${ }^{1} \mathrm{H}$ NMR and (b) ${ }^{1} \mathrm{H}$ DOSY spectra $\left(\mathrm{CDCl}_{3}, 400 \mathrm{MHz}, 298 \mathrm{~K}\right)$ product from attempted synthesis of star-[(PVC- $b$-PHABP; $\left.(\mathrm{PHABP})_{2}\right]\left(M_{\mathrm{n}}=23300, \emptyset=1.51\right)$ copolymer. The DOSY spectrum is consistent with presence of a significant amount of PHABP homopolymer and PVC. 
4.4 star-[(PVC;(PBTEM)2]. The DOSY peaks for the PBTEM and PVC components have the same spin correlation time (Figure S11b) consistent with their being part of the same structure, namely, star[(PVC;(PBTEM) $\left.)_{2}\right]$.

(a)

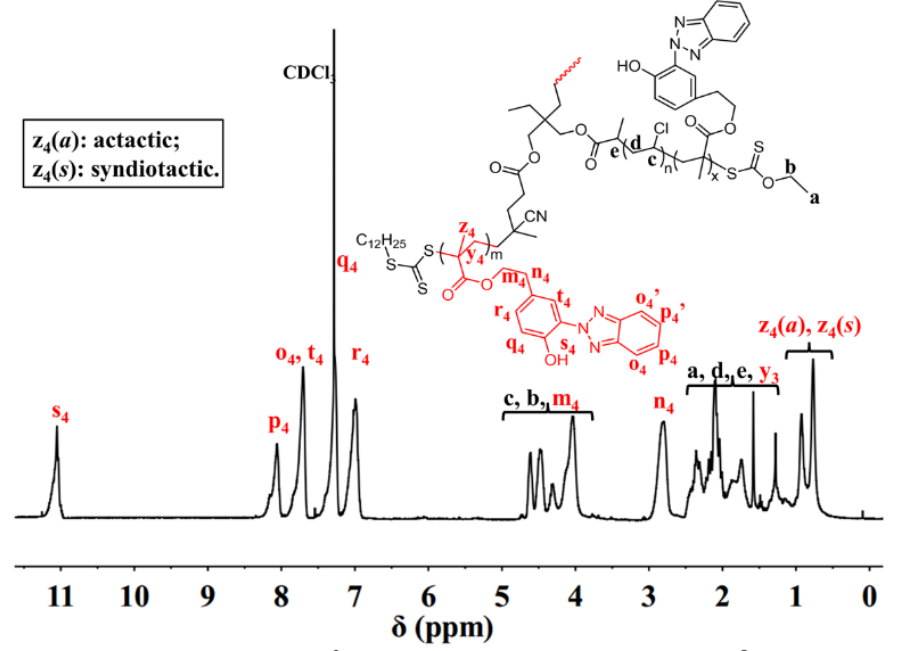

(b)

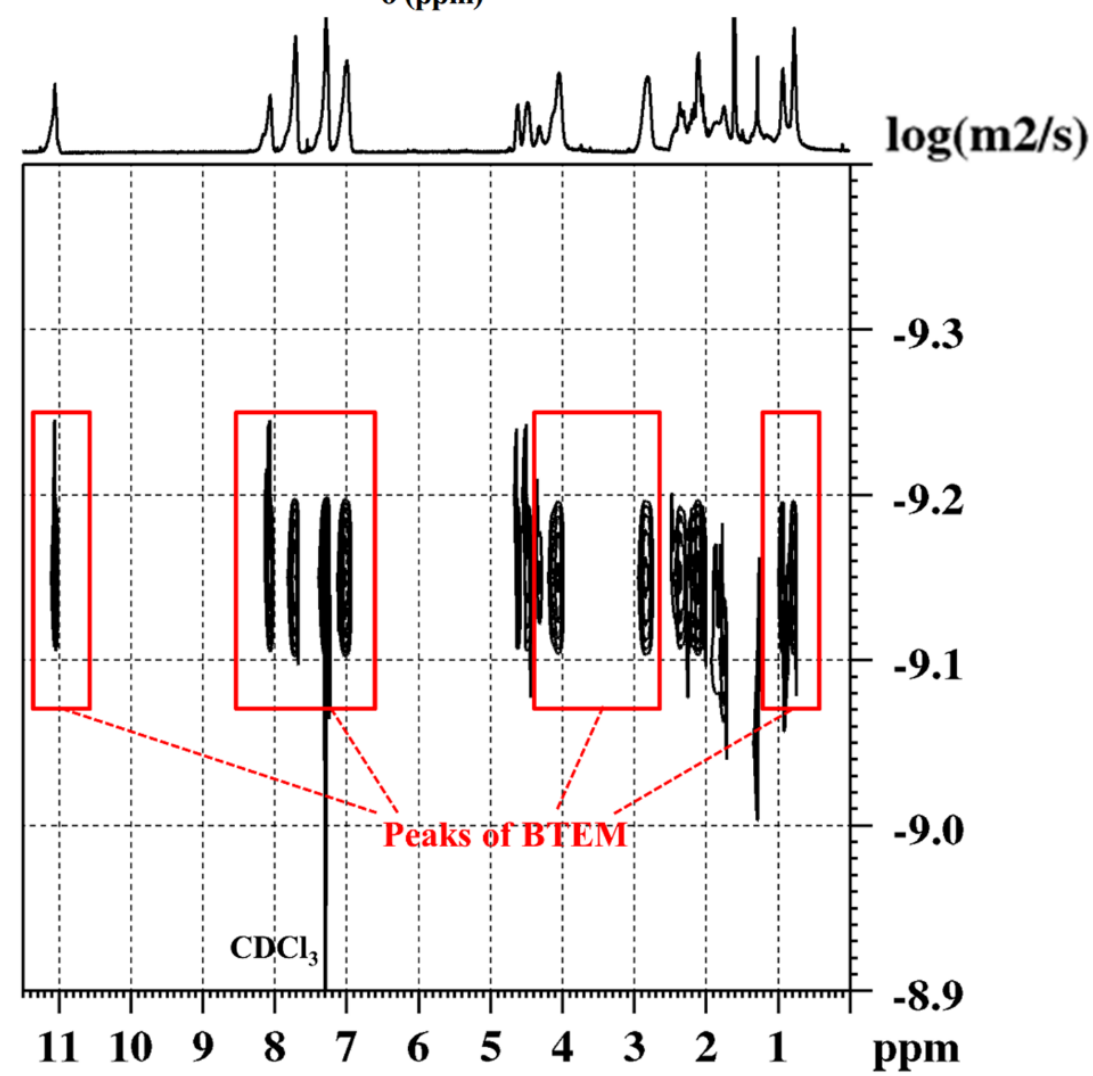

Figure S11. (a) ${ }^{1} \mathrm{H}$ NMR and (b) ${ }^{1} \mathrm{H}$ DOSY spectra $\left(\mathrm{CDCl}_{3}, 400 \mathrm{MHz}, 298 \mathrm{~K}\right)$ for star-[(PVC;(PBTEM) $]$ $\left(M_{\mathrm{n}}=24700, \emptyset=1.58\right)$ copolymer. 
4.5 star-[(PVC-b-PVB;(PVBP $\left.)_{2}\right]$. The DOSY peaks for the PVB and PVC components have the same spin correlation time (Figure S12b) consistent with their being part of the same structure, namely, star-[(PVC-bPVB;(PVBP) 2$]$

(a)

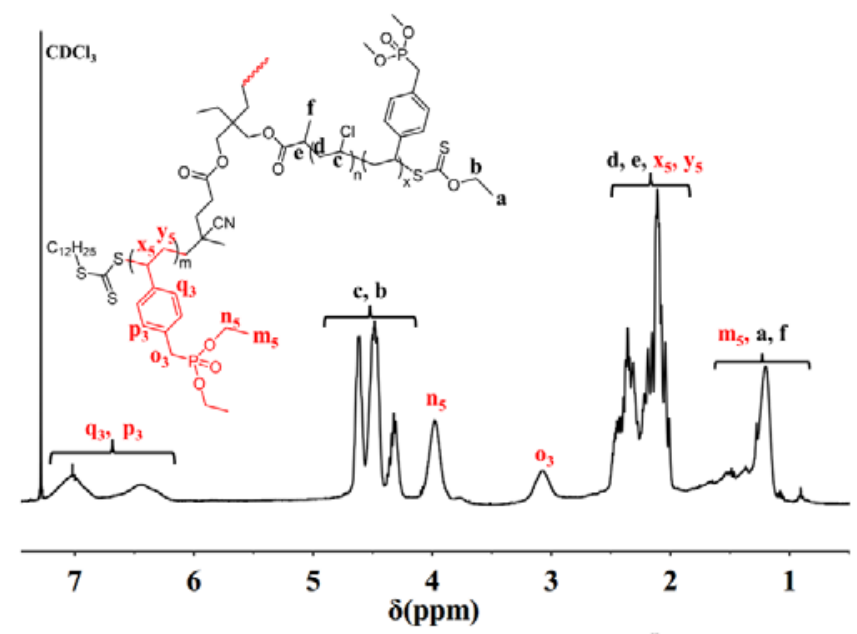

(b)

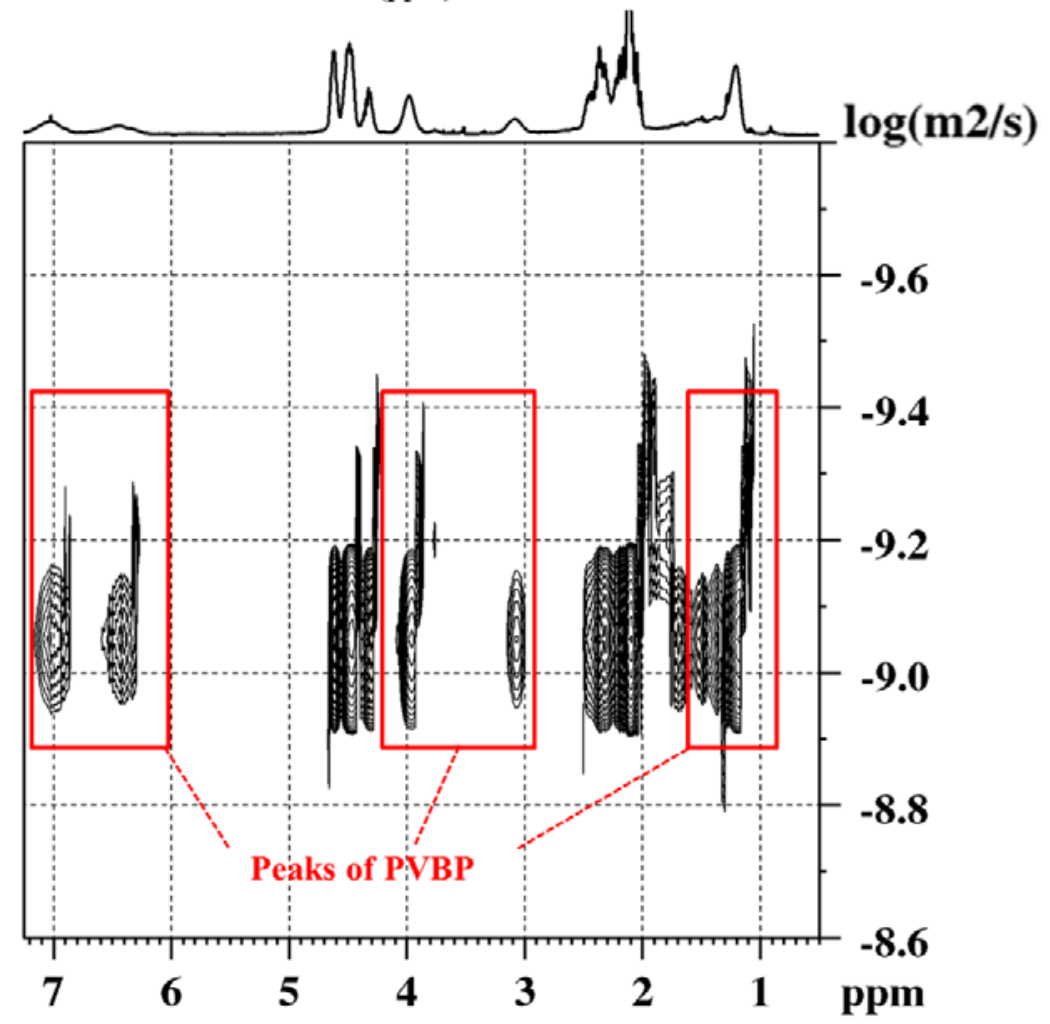

Figure S12. (a) ${ }^{1} \mathrm{H}$ NMR and (b) ${ }^{1} \mathrm{H}$ DOSY spectra $\left(\mathrm{CDCl}_{3}, 400 \mathrm{MHz}, 298 \mathrm{~K}\right)$ for star-[(PVC- $b$-PVB;(PVBP $\left.)_{2}\right]$ $\left(M_{\mathrm{n}}=18200, Ð=1.46\right)$ copolymer. 
4.6 star-[(PVC;(PDEMMP)2]. The DOSY peaks for the PVB and PVC components have the same spin correlation time (Figure S13b) consistent with their being part of the same structure, namely, star[(PVC;(PDEMMP) $\left.)_{2}\right]$

(a)

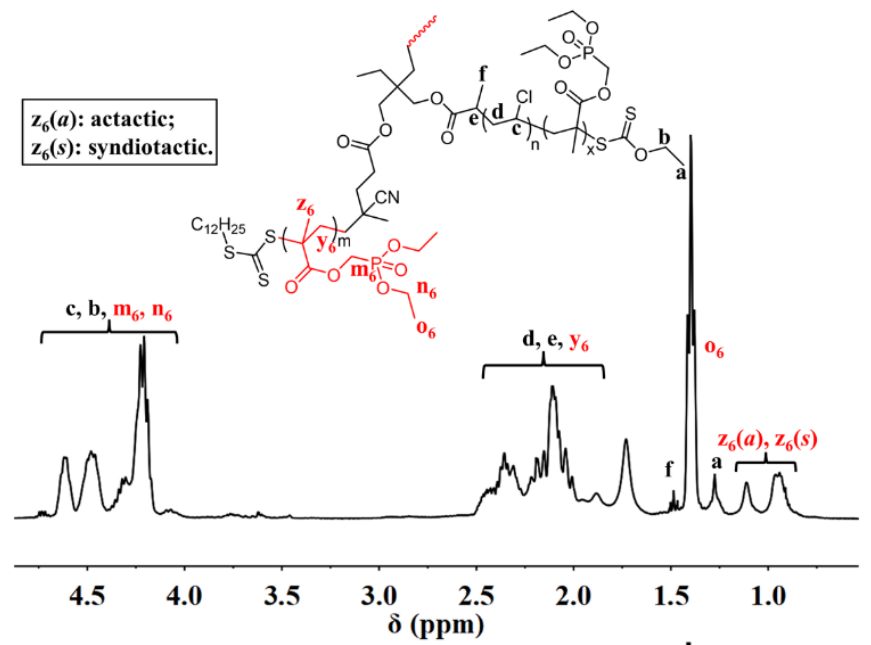

(b)

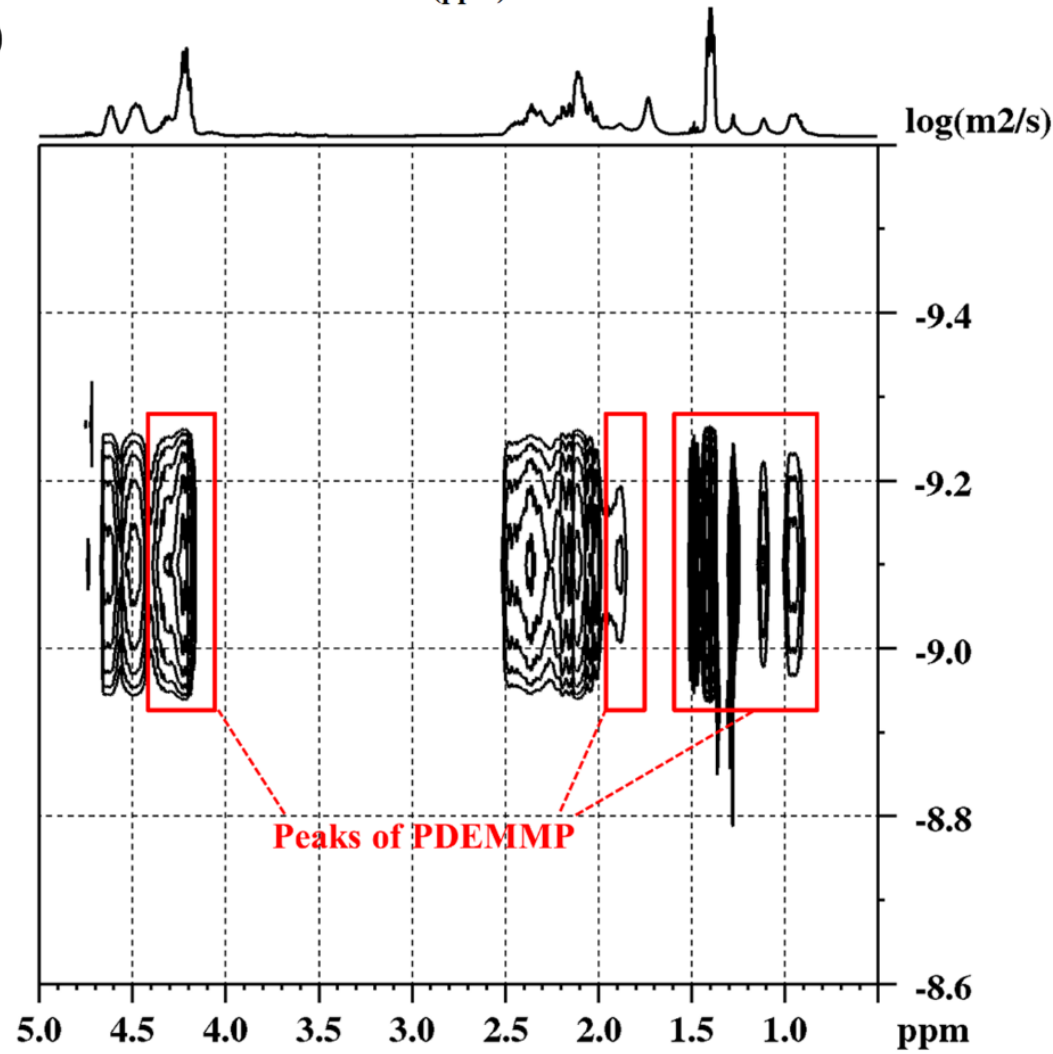

Figure S13. (a) ${ }^{1} \mathrm{H}$ NMR and (b) ${ }^{1} \mathrm{H}$ DOSY spectra $\left(\mathrm{CDCl}_{3}, 400 \mathrm{MHz}, 298 \mathrm{~K}\right)$ for star-[(PVC;(PDEMMP) $]$ $\left(M_{\mathrm{n}}=17900, D=1.54\right)$ copolymer.

\section{GPC characterization of $\mathrm{AB}_{2} 3$-mikto-arm stars}

The GPC traces shown in Figure S14 are consistent with chain extension however the peaks of the stars are not fully resolved from that of the PVC precursor thus we cannot make a definitive statement on purity based on this data. 


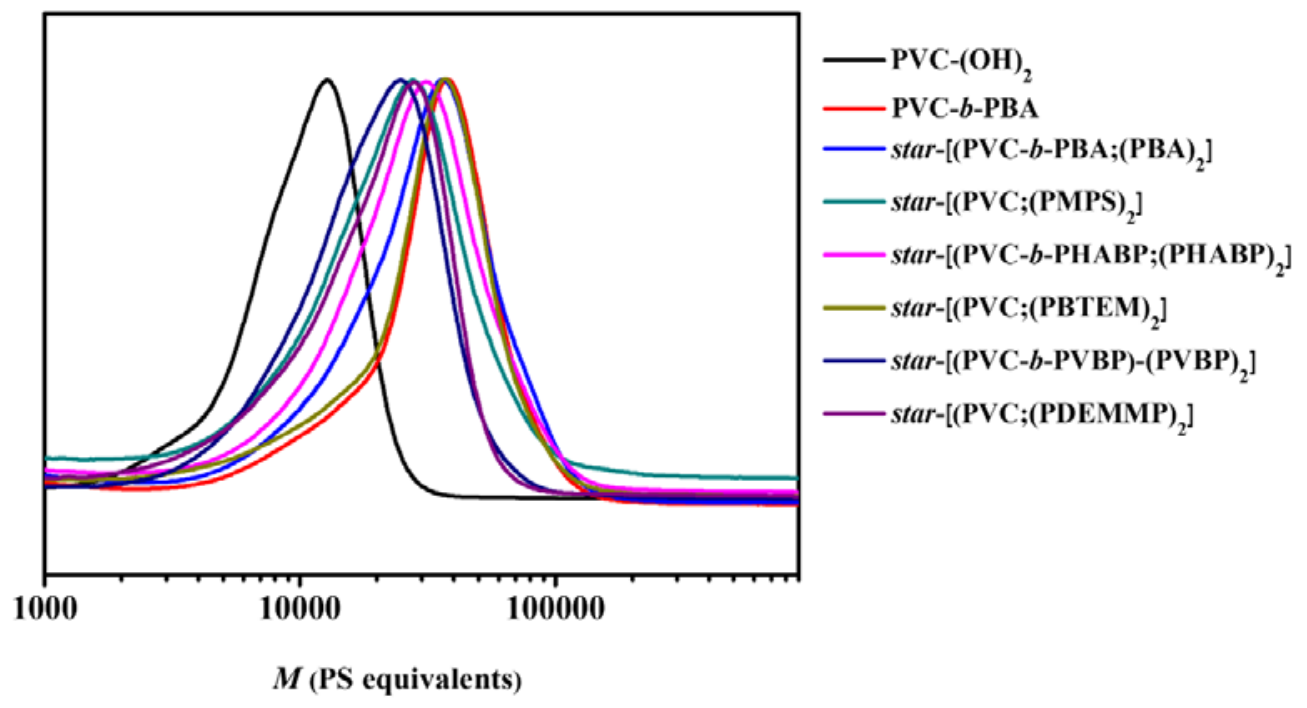

Figure S14. GPC traces of PVC-(OH $)_{2}$ and prepared mikto-arm star polymers

\section{Migration resistance experiments for PVC blends}

(a)

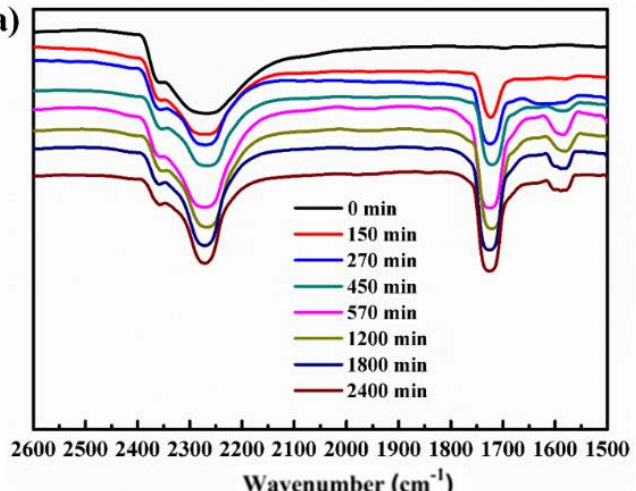

(c)

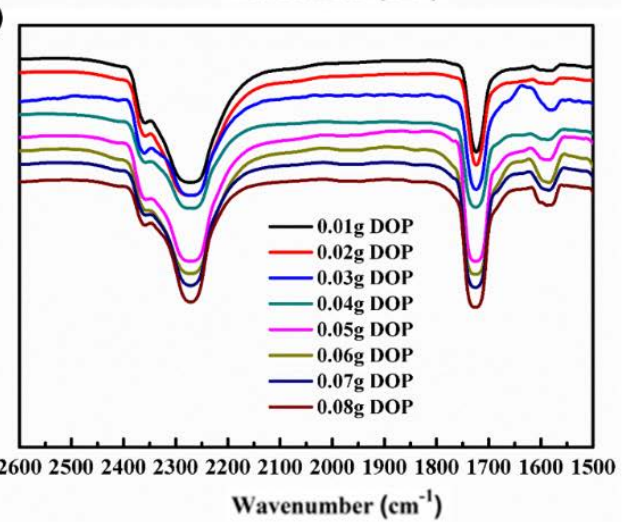

(b)

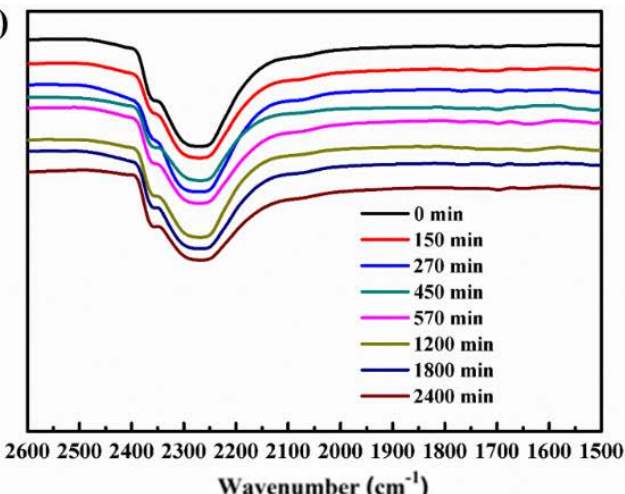

(d)

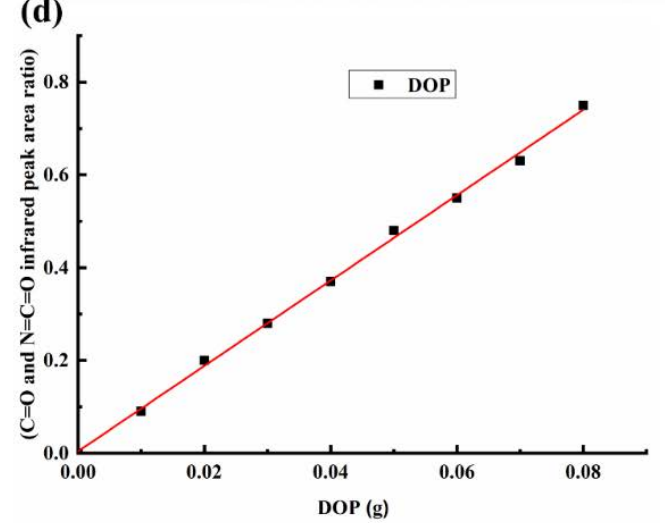

Figure S15. Infrared spectra of extraction liquid from (a) DOP (0.2g) and (b) star-[(PVC-b-PBA;(PBA) $\left.{ }_{2}\right]$ (0.2g) plasticized PVC (0.5g) at different extraction time; (c) Infrared spectra of DOP and 1,6-hexamethylene diisocyanate $(0.02 \mathrm{~g})$ in $10 \mathrm{~mL} n$-hexane solution; (d) calibration curve of the DOP in $10 \mathrm{~mL} n$-hexane solution. 


\section{Thermogravimetric analysis (TGA) for PVC and star-[(PVC;(PMPS)2]}

Table S3. Weight loss data for PVC and star-[(PVC; $\left.(\mathrm{PMPS})_{2}\right]\left(M_{\mathrm{n}}=22200, D=1.50\right)$ observed by thermogravimetric analysis (TGA).

\begin{tabular}{|c|c|c|c|}
\hline Sample & $\mathrm{T}_{0.1}\left({ }^{\circ} \mathrm{C}\right)^{\mathrm{a}}$ & $\mathrm{T}_{0.5}\left({ }^{\circ} \mathrm{C}\right)^{\mathrm{b}}$ & Residue (\%) \\
\hline PVC & 217 & 272 & 7.5 \\
\hline star-[(PVC;(PMPS) $\left.)_{2}\right] / 5 w t \%$ TEOS & 260 & 458 & 33.7 \\
\hline star-[(PVC;(PMPS $\left.)_{2}\right] /$ 10wt\% TEOS & 274 & 479 & 38.5 \\
\hline $\begin{array}{c}\text { PVC }+ \\
\left.\text { star-[(PVC;(PMPS })_{2}\right] / \text { 10wt\% TEOS }\end{array}$ & 246 & 423 & 25.3 \\
\hline
\end{tabular}

a. $\mathrm{T}_{0.1}$, temperature of $10 \%$ weight loss; ${ }^{\text {b. }} \mathrm{T}_{0.5}$, temperature of $50 \%$ weight loss. 


\section{Molar mass of PVC}

The literature ${ }^{7}$ suggests that PVC homopolymer molar mass values in PS equivalents may be high by 30\% with respect to actual molar mass. However, this is based on analysis of samples of higher molar mass than those produced in this work We note that in some other recent work, where similar molar mass values were targeted to those in the present work, there is relatively good correspondence between found molar mass in PS-equivalents and predicted molar mass values. ${ }^{8}$

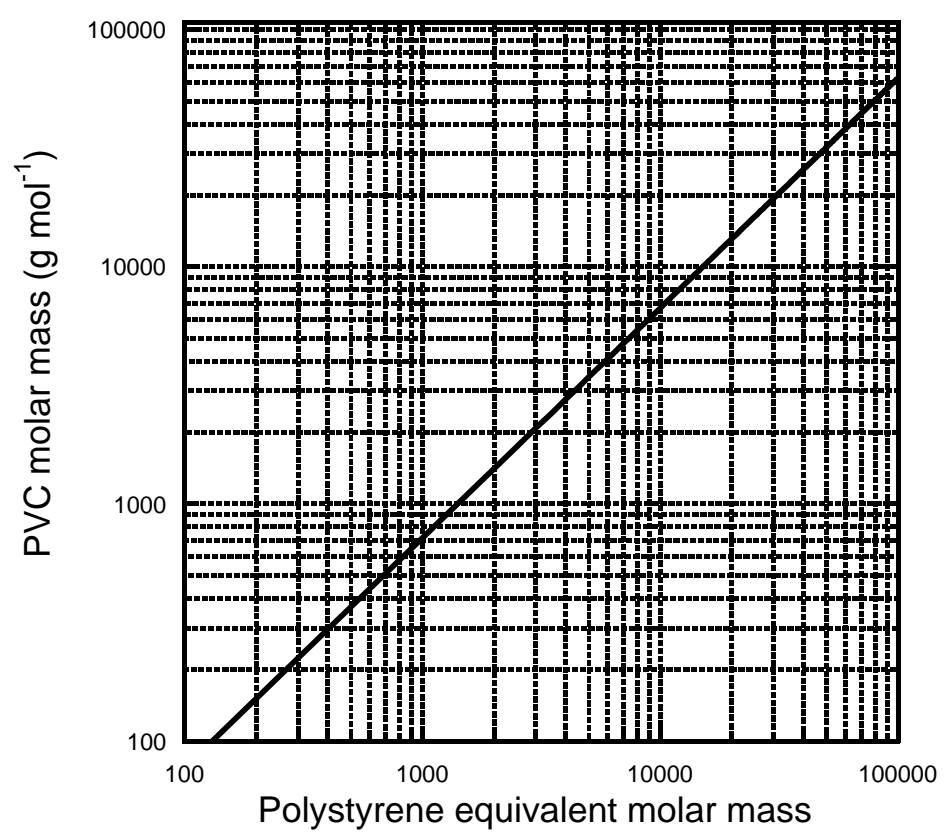

Figure S16. Correlation between absolute molar mass for PVC and GPC molar mass in polystyrene equivalents suggested by the Mark-Houwink relationship and data from the literature. ${ }^{7}$

\section{References}

(1) Sun, Z.; Choi, B.; Feng, A.; Moad, G.; Thang, S. H., Nonmigratory Poly(Vinyl Chloride)-BlockPolycaprolactone Plasticizers and Compatibilizers Prepared by Sequential RAFT and Ring-Opening Polymerization (RAFT-F-ROP). Macromolecules 2019, 52 (4), 1746-1756.

(2) Allinger, N. L.; Yuh, Y. H., MM2, QCPE Program No. 3951980.

(3) Murguia, M. C.; Vaillard, S. E.; Grau, R. J., A Facile, Selective Preparation of Monoketals from Pentaerythritol and Ketones. Synthesis 2001, 32 (39), 1093-1097.

(4) Zhang, L.; Zhang, W.; Zhou, N.; Zhu, J.; Zhang, Z.; Cheng, Z.; Zhu, X., Preparation and Characterization of Linear and Miktoarm Star Side-Chain Liquid Crystalline Block Copolymers with PMethoxyazobenzene Moieties Via a Combination of ATRP and ROP. J. Macromol. Sci., Part A: Pure Appl.Chem 2009, 46 (9), 876-885.

(5) Priftis, D.; Pitsikalis, M.; Hadjichristidis, N., Miktoarm Star Copolymers of Poly(€-Caprolactone) from a Novel Heterofunctional Initiator. J. Polym. Sci., Part A, Polym. Chem. 2007, 45 (22), 5164-5181.

(6) Hiller, W., Quantitative Studies of Block Copolymers and their Containing Homopolymer Components by Diffusion Ordered Spectroscopy. Macromol. Chem. Phys. 2019, 220 (17), 1900255.

(7) Skillicorn, D. E.; Perkins, G. G. A.; Slark, A.; Dawkins, J. V., Molecular Weight and Solution Viscosity Characterization of Pvc. J. Vinyl Technol. 1993, 15 (2), 105-108.

(8) Huang, Z.; Pan, P.; Bao, Y., Solution and Aqueous Miniemulsion Polymerization of Vinyl Chloride Mediated by a Fluorinated Xanthate. J. Polym. Sci., Part A, Polym. Chem. 2016, 54 (14), 2092-2101. 